\title{
Association of serum total cholesterol and left ventricular ejection fraction in patients with heart failure caused by coronary heart disease
}

\author{
Yan Liu, Zirui Hao, Chun Xiao, Ling Liu, Huocheng Liao
}

Department of Cardiology, The Third People's Hospital of Huizhou, Huizhou, Guangdong Province, China

Submitted: 31 July 2017

Accepted: 10 September 2017

Arch Med Sci 2018; 14, 5: 988-994

DOI: https://doi.org/10.5114/aoms.2017.70660

Copyright $@ 2017$ Termedia \& Banach

\section{Abstract}

Introduction: The aim was to evaluate the association of serum total cholesterol (TC) level and left ventricular ejection fraction (LVEF) in patients with heart failure (HF) caused by coronary heart disease (CHD).

Material and methods: A total of 236 participants were enrolled. Participants were divided into severely reduced $(\leq 35 \%)$ and moderately reduced (>35\%) LVEF groups and the between-group difference was evaluated. Multivariate regression analysis was used to evaluate the association between LVEF and parameters of interest. Linear regression analysis was applied to analyze the odds ratio of per 1-SD increase in serum TC level for LVEF change. Results: Mean age was 57.3 years and males accounted for $58.1 \%$. Mean serum TC level was $4.6 \mathrm{mmol} / \mathrm{l}$, albumin (ALB) $33.6 \mathrm{~g} / \mathrm{l}$, and C-reactive protein (CRP) $11.4 \mathrm{mg} / \mathrm{l}$. Mean LVEF was 38.3\%. Compared to high-reduced LVEF group, participants in moderate-reduced LVEF group had significantly higher TC $(4.8 \pm 0.9 \mathrm{mmol} / \mathrm{l}$ vs. $4.4 \pm 0.7 \mathrm{mmol} / \mathrm{l})$ and ALB $(35.8 \pm 6.7 \mathrm{~g} / \mathrm{l}$ vs. 31.4 $\pm 6.0 \mathrm{~g} / \mathrm{l})$ but lower CRP $(9.6 \pm 4.7 \mathrm{mg} / \mathrm{l}$ vs. $14.2 \pm 7.0 \mathrm{mg} / \mathrm{l})$ levels $(p<0.05$ for all comparisons). Increased TC and ALB levels were associated with higher LVEF, and increased CRP level was associated with lower LVEF. After adjusted for CRP, although per 1-SD increase in TC level was still associated with an increment in $4 \%$ in LVEF, it did not achieve achieve statistic significance.

Conclusions: In patients with HF caused by CHD, higher serum TC level appeared to be associated with higher LVEF, which might be associated with systemic inflammation improvement.

Key words: heart failure, coronary heart disease, total cholesterol.

\section{Introduction}

Heart failure (HF), featured by cardiac systolic or diastolic dysfunction, is a major public health problem around the world [1-3]. Although medications such as angiotensin-converting enzyme inhibitors or angiotensin receptor blockers (ACEI/ARB), $\beta$-blockers and aldosterone antagonists have been broadly applied to patients with $\mathrm{HF}$, the mortality rate is still high and nearly $50 \%$ of HF patients die within the first 5 years after the initiation of clinical symptoms [1-3].

Prior epidemiological studies indicate that dyslipidemia contributes to the initiation and progress of coronary heart disease (CHD) [4-6], which is the major cause of $\mathrm{HF}$ in both developed and developing countries.

\author{
Corresponding author: \\ Zirui Hao \\ Department of Cardiology \\ Third People's \\ Hospital of Huizhou \\ 1 Qiaodongxuebei St \\ Huizhou 516000, China \\ Phone: +86 7522255120 , \\ ext. 8164 \\ Fax: +867522255120 \\ ext. 8756 \\ E-mail: doctorliuyan168@ \\ sina.com
}


Numerous randomized controlled trials have consistently demonstrated that reduced serum total cholesterol (TC) and low-density lipoprotein cholesterol (LDL-C) levels confer both short-term and long-term benefits to patients with dyslipidemia [7-10]. Notably, in patients with documented CHD, regardless of their baseline serum cholesterol level, statins were recommended by the 2013 AHA/ACC guideline as the cornerstone therapy for secondary prevention of ischemic events [11]. However, in patients with HF caused by CHD, previous observational studies indicate that high serum cholesterol level appeared to be associated with better cardiovascular outcomes compared to those with low serum cholesterol level $[12,13]$, and the underlying mechanisms are multifactorial and not fully understood yet [14].

In the current study, we used a cross-sectional design to investigate the association of serum TC level and left ventricular ejection fraction (LVEF) in HF caused by CHD. In addition, the potential mechanisms was also explored concurrently.

\section{Material and methods}

\section{Studied participants' enrolment}

Participants' enrolments were performed between January of 2016 to April of 2017 and the current study was approved by the Clinical Research Ethic Committee of the Third People's Hospital of Huizhou. Informed consent was provided before enrolment and all participants were treated in accordance with the Declaration of Helsinki. Inclusion criteria were as follows: angiographic diagnosis of CHD, presence of chronic HF symptoms assessed in accordance with the criteria of the New York Heart Association classification, and had LVEF $<45 \%$ assessed during indexed hospitalization. Exclusion criteria were as follows: admission with acute decompensated HF, treated with intravenous vasoactive agents such as dopamine or nitroprusside sodium during hospitalization, presence of acute coronary syndrome during indexed admission, or presence of infection such as pneumonia or cystitis.

\section{Clinical characteristics and biochemical data collection}

Clinical characteristics including age, gender, smoking status, height and weight used for calculation of body mass index (BMI), and systolic/ diastolic blood pressure (SBP/DBP) and heart rate $(H R)$ at rest during admission were extracted from medical records. Risk factors of HF including hypertension and diabetes mellitus were recorded based on previous documented diagnosis, or current anti-hypertensive or anti-diabetic therapy, respectively. Co-morbidities including ischemic stroke and peripheral artery disease (PAD) were diagnosed based on patients' clinical symptoms and signs, and documented imaging evidence derived from computed tomography or vascular Doppler ultrasound. Current medication usage was collected by two independent investigators.

Fasting venous blood was drawn for assessment of lipid profiles, fasting plasma glucose (FPG), glycated hemoglobin $A_{1 c}\left(H_{b A}\right)$, C-reactive protein $(\mathrm{CRP})$, creatinine $(\mathrm{Cr})$, liver function panel (alanine aminotransferase (ALT) and aspartate aminotransferase (AST)), albumin (ALB) and N-terminal probrain natriuretic peptide (NT-proBNP) levels.

\section{Echocardiography assessment}

Participants were asked to lie down in the left recumbent position. The left ventricular volumes from apical 2 and 4 chamber views were captured through tracing the endocardial border of left ventricle using 2D transthoracic echocardiography and the machine automatically calculated LVEF using the biplane Simpson's method (Philips EPIQ 7).

\section{Statistical analysis}

Continuous variables were presented as mean \pm SD and categorical variables were presented as the number and percentage of cases. Statistical significance of differences was analyzed using Student's $t$-test for continuous variables, and the $\chi^{2}$ or Fisher's exact test was used for comparison of categorical variables. Univariate and multivariate regression analysis was used to analyze the association between LVEF and parameters of interest. In brief, based on a previous report [15], parameters of interest included age and gender, smoking status and BMI, comorbidities such as diabetes mellitus and hypertension, laboratory data such as liver function panel (such as ALT) and glucose level, and use of medications such as ACEI/ARB which were considered in relation to cardiac function. Linear regression analysis was applied to analyze the odds ratio (OR) and associated $95 \%$ confidence intervals $(\mathrm{Cl})$ of per $1-\mathrm{SD}$ increase in serum TC levels for LVEF change. Statistical analysis was conducted using SPSS 17.0 (SPSS Inc, Chicago, IL). All of the statistical tests were two-sided and considered statistically significant if $p<0.05$.

\section{Results}

\section{General characteristics}

A total of 236 participants were enrolled and the general characteristics are presented in Table I. The mean age was 57.3 years, male participants accounted for $58.1 \%$, and the mean BMI was $22.7 \mathrm{~kg} / \mathrm{m}^{2}$. Regarding the risk factors and 
Table I. General characteristics $(N=236)$

\begin{tabular}{|c|c|}
\hline Variable & Value \\
\hline Male, $n(\%)$ & $137(58.1)$ \\
\hline Age, mean \pm SD [years] & $57.3 \pm 11.7$ \\
\hline Current smoker, $n(\%)$ & $94(39.8)$ \\
\hline Height, mean \pm SD $[\mathrm{cm}]$ & $164.7 \pm 7.5$ \\
\hline Weight, mean \pm SD [kg] & $54.2 \pm 16.8$ \\
\hline $\mathrm{BMI}$, mean $\pm \mathrm{SD}\left[\mathrm{kg} / \mathrm{m}^{2}\right]$ & $22.7 \pm 5.4$ \\
\hline Hypertension, $n$ (\%) & $148(62.7)$ \\
\hline Diabetes mellitus, $n$ (\%) & $102(43.2)$ \\
\hline Ischemic stroke, $n(\%)$ & $16(6.8)$ \\
\hline PAD, $n(\%)$ & $27(11.4)$ \\
\hline $\mathrm{SBP}$, mean $\pm \mathrm{SD}[\mathrm{mm} \mathrm{Hg}]$ & $127.5 \pm 12.6$ \\
\hline $\mathrm{DBP}$, mean $\pm \mathrm{SD}[\mathrm{mm} \mathrm{Hg}]$ & $62.3 \pm 10.2$ \\
\hline $\mathrm{HR}$, mean $\pm \mathrm{SD}[\mathrm{bpm}]$ & $85.3 \pm 14.4$ \\
\hline $\mathrm{TC}$, mean $\pm \mathrm{SD}[\mathrm{mmol} / \mathrm{l}]$ & $4.6 \pm 0.9$ \\
\hline $\mathrm{TG}$, mean $\pm \mathrm{SD}[\mathrm{mmol} / \mathrm{l}]$ & $1.6 \pm 0.8$ \\
\hline LDL-C, mean \pm SD $[\mathrm{mmol} / \mathrm{l}]$ & $2.4 \pm 0.6$ \\
\hline $\mathrm{HDL}-\mathrm{C}$, mean $\pm \mathrm{SD}[\mathrm{mmol} / \mathrm{l}]$ & $1.0 \pm 0.3$ \\
\hline $\mathrm{Cr}$, mean $\pm \mathrm{SD}[\mu \mathrm{mol} / \mathrm{l}]$ & $87.3 \pm 12.6$ \\
\hline $\mathrm{ALB}$, mean $\pm \mathrm{SD}[\mathrm{g} / \mathrm{ll}]$ & $33.6 \pm 6.3$ \\
\hline AST, mean \pm SD $[\mathrm{U} / \mathrm{I}]$ & $47 \pm 12$ \\
\hline $\mathrm{ALT}$, mean $\pm \mathrm{SD}[\mathrm{U} / \mathrm{l}]$ & $54 \pm 15$ \\
\hline $\mathrm{FPG}$, mean $\pm \mathrm{SD}[\mathrm{mmol} / \mathrm{l}]$ & $5.6 \pm 0.9$ \\
\hline $\mathrm{HbA}_{1 \mathrm{c}}(\%)$ & $6.4 \pm 0.7$ \\
\hline $\mathrm{CRP}$, mean $\pm \mathrm{SD}[\mathrm{mg} / \mathrm{l}]$ & $11.4 \pm 5.2$ \\
\hline NT-proBNP, mean \pm SD $[\mathrm{pg} / \mathrm{ml}]$ & $1422 \pm 376$ \\
\hline ACEI/ARB, $n(\%)$ & $206(87.3)$ \\
\hline$\beta$-Blocker, $n(\%)$ & $199(84.3)$ \\
\hline Spironolactone, $n(\%)$ & $85(36.0)$ \\
\hline $\mathrm{CCB}, n(\%)$ & $32(13.6)$ \\
\hline Diuretics, $n(\%)$ & $197(83.5)$ \\
\hline Statins, $n(\%)$ & $219(92.8)$ \\
\hline Anti-platelet, $n(\%)$ & $236(100)$ \\
\hline Anti-diabetic medications, $n(\%)$ & $84(35.6)$ \\
\hline Insulin, $n(\%)$ & $22(9.3)$ \\
\hline LVEF, mean \pm SD $(\%)$ & $38.3 \pm 5.8$ \\
\hline NYHA-I/II, $n(\%)$ & $100(42.4)$ \\
\hline NYHA-III/IV, $n$ (\%) & $136(57.6)$ \\
\hline
\end{tabular}

$B M I$ - body mass index (weight in kilograms divided by height in meters squared), PAD - peripheral artery disease, SBP/DBP systolic/diastolic blood pressure, $H R$ - heart rate, bpm - beats per minute, TC - total cholesterol, TG - triglyceride, LDL-C - lowdensity lipoprotein cholesterol, HDL-C - high-density lipoprotein cholesterol, $\mathrm{Cr}$-creatinine, ALB - albumin, AST - aspartate aminotransferase, $A L T$ - alanine aminotransferase, FPG - fasting plasma glucose, $H b A_{1 c}$ - glycated hemoglobin $A_{1 c}, C R P-C$-reactive protein $N T$-proBNP - N-terminal pro-brain natriuretic peptide, ACEI/ARB - angiotensin-converting enzyme inhibitor/angiotensin receptor blocker, CCB - calcium channel blocker, LVEF - left ventricular ejection fraction, NYHA - New York Heart Association. co-morbidities, $62.7 \%, 43.2 \%, 6.8 \%$ and $11.4 \%$ of participants had hypertension, diabetes mellitus, ischemic stroke and peripheral artery disease, respectively. Regarding the biochemical parameters, the mean serum TC level was $4.6 \mathrm{mmol} / \mathrm{l}$, ALB $33.6 \mathrm{~g} / \mathrm{l}$, ALT $54 \mathrm{U} / \mathrm{l}, \mathrm{CRP} 11.4 \mathrm{mg} / \mathrm{l}$, and NT-proBNP $1422 \mathrm{pg} / \mathrm{ml}$, respectively. The mean LVEF was $38.3 \%$ and $57.6 \%$ of participants had cardiac function of NYHA classification of III/IV. Nearly $87.3 \%$, $84.3 \%, 36.0 \%, 83.5 \%$ and $92.8 \%$ of participants were treated with ACEI/ARB, $\beta$-blockers, spironolactone, diuretics and statins.

\section{Comparisons between severely reduced and moderately reduced LVEF groups}

Participants were separated into two groups based on the cutoff values of LVEF $\leq 35 \%$ and $>35 \%$. As presented in Table II, compared to the severely reduced LVEF group, participants in the moderately reduced LVEF group were younger and had significantly higher serum TC $(4.8 \pm 0.9 \mathrm{mmol} / \mathrm{l} \mathrm{vs}$. $4.4 \pm 0.7 \mathrm{mmol} / \mathrm{l})$ and albumin (ALB) $(35.8 \pm 6.7 \mathrm{~g} / \mathrm{l}$ vs. $31.4 \pm 6.0 \mathrm{~g} / \mathrm{l})$ levels, while they had significantly lower heart rate, serum CRP $(9.6 \pm 4.7 \mathrm{mg} / \mathrm{l}$ vs. $14.2 \pm 7.0 \mathrm{mg} / \mathrm{l})$ and NT-proBNP $(1394 \pm 344 \mathrm{pg} / \mathrm{ml}$ vs. $1547 \pm 401 \mathrm{pg} / \mathrm{l})$ levels. Except for the higher percentage of ACEI/ARB and spironolactone usage in the moderately reduced versus severely reduced LVEF group, medication usage between groups was not significantly different. Expectedly, the mean LVEF level was significantly higher and the percentage of participants with the NYHA classification of III/IV was lower in the moderately reduced LVEF group.

\section{Association of LVEF and parameters of interest}

Univariate and multivariate regression analyses were applied to evaluate the association of LVEF and parameters of interest. As presented in Table III, in the univariate regression analysis, variables including age, TC, ALB, CRP, NT-proBNP, ACEI/ARB and spironolactone were significantly associated with LVEF. In the multivariate regression analysis, increased serum levels of TC and ALB and usage of ACEI/ARB and spironolactone were significantly associated with higher LVEF, and increased serum CRP level was associated with lower LVEF.

\section{Association of serum TC level and LVEF}

The association of serum TC level and LVEF was assessed using linear regression analysis. As presented in Table IV, overall, per 1 - SD increased serum TC level was associated with an increment of $21 \%$ to $8 \%$ in LVEF from the unadjusted model to model 3. However, after further adjustment for CRP, although per 1 - SD increased serum TC level 
Table II. Comparisons between severely reduced and moderately reduced LVEF groups

\begin{tabular}{|c|c|c|}
\hline Variables & $\begin{array}{l}\text { Severely } \\
\text { reduced } \\
(n=86)\end{array}$ & $\begin{array}{c}\text { Moderately } \\
\text { reduced } \\
(n=150)\end{array}$ \\
\hline Male, $n(\%)$ & $50(58.1)$ & $87(58)$ \\
\hline Age, mean \pm SD [years] & $60.2 \pm 9.6$ & $55.4 \pm 12.2^{*}$ \\
\hline Current smoker, $n(\%)$ & $34(39.5)$ & $60(40)$ \\
\hline Height, mean \pm SD $[\mathrm{cm}]$ & $163.2 \pm 7.8$ & $165.0 \pm 7.0$ \\
\hline Weight, mean \pm SD $[\mathrm{kg}]$ & $53.9 \pm 15.4$ & $54.6 \pm 17.1$ \\
\hline $\mathrm{BMI}$, mean $\pm \mathrm{SD}\left[\mathrm{kg} / \mathrm{m}^{2}\right]$ & $22.0 \pm 5.2$ & $23.2 \pm 6.1$ \\
\hline Hypertension, $n$ (\%) & $54(62.7)$ & $94(62.7)$ \\
\hline Diabetes mellitus, $n(\%)$ & $38(44.2)$ & $64(42.7)$ \\
\hline Ischemic stroke, $n$ (\%) & $6(7.0)$ & $10(6.7)$ \\
\hline PAD, $n(\%)$ & $10(11.6)$ & $17(11.3)$ \\
\hline $\mathrm{SBP}$, mean $\pm \mathrm{SD}[\mathrm{mm} \mathrm{Hg}]$ & $125.4 \pm 12.0$ & $129.0 \pm 12.8$ \\
\hline $\mathrm{DBP}$, mean $\pm \mathrm{SD}[\mathrm{mm} \mathrm{Hg}]$ & $61.4 \pm 10.7$ & $63.5 \pm 9.9$ \\
\hline $\mathrm{HR}$, mean $\pm \mathrm{SD}[\mathrm{bpm}]$ & $89.6 \pm 12.8$ & $81.8 \pm 14.9^{*}$ \\
\hline $\mathrm{TC}$, mean $\pm \mathrm{SD}[\mathrm{mmol} / \mathrm{l}]$ & $4.4 \pm 0.7$ & $4.8 \pm 0.9^{\star}$ \\
\hline $\mathrm{TG}$, mean $\pm \mathrm{SD}[\mathrm{mmol} / \mathrm{l}]$ & $1.6 \pm 0.5$ & $1.7 \pm 0.9$ \\
\hline $\begin{array}{l}\text { LDL-C, mean } \pm \text { SD } \\
{[\mathrm{mmol} / \mathrm{l}]}\end{array}$ & $2.3 \pm 0.5$ & $3.5 \pm 0.6$ \\
\hline $\begin{array}{l}\mathrm{HDL}-\mathrm{C}, \text { mean } \pm \mathrm{SD} \\
{[\mathrm{mmol} / \mathrm{l}]}\end{array}$ & $1.0 \pm 0.4$ & $1.0 \pm 0.3$ \\
\hline $\mathrm{Cr}$, mean $\pm \mathrm{SD}[\mu \mathrm{mol} / \mathrm{l}]$ & $86.4 \pm 12.2$ & $87.9 \pm 12.8$ \\
\hline $\mathrm{ALB}$, mean $\pm \mathrm{SD}[\mathrm{g} / \mathrm{l}]$ & $31.4 \pm 6.0$ & $35.8 \pm 6.7^{\star}$ \\
\hline $\mathrm{AST}$, mean $\pm \mathrm{SD}[\mathrm{U} / \mathrm{l}]$ & $49 \pm 14$ & $45 \pm 11$ \\
\hline $\mathrm{ALT}$, mean $\pm \mathrm{SD}[\mathrm{U} / \mathrm{I}]$ & $60 \pm 18$ & $49 \pm 13^{*}$ \\
\hline $\mathrm{FPG}$, mean $\pm \mathrm{SD}[\mathrm{mmol} / \mathrm{l}]$ & $5.7 \pm 0.8$ & $5.6 \pm 0.9$ \\
\hline $\mathrm{HbA}_{1 \mathrm{c}}(\%)$ & $6.5 \pm 0.8$ & $6.4 \pm 0.6$ \\
\hline $\mathrm{CRP}$, mean $\pm \mathrm{SD}[\mathrm{mg} / \mathrm{l}]$ & $14.2 \pm 7.0$ & $9.6 \pm 4.7^{\star}$ \\
\hline $\begin{array}{l}\text { NT-proBNP, mean } \pm \text { SD } \\
{[\mathrm{pg} / \mathrm{ml}]}\end{array}$ & $1547 \pm 401$ & $1394 \pm 344^{*}$ \\
\hline ACEI/ARB, $n(\%)$ & $70(81.4)$ & $136(90.7)^{\star}$ \\
\hline$\beta$-Blocker, $n(\%)$ & $74(86.0)$ & $125(83.3)$ \\
\hline Spironolactone, $n(\%)$ & $28(32.6)$ & $57(38.0)^{\star}$ \\
\hline $\mathrm{CCB}, n(\%)$ & $12(13.9)$ & $20(13.3)$ \\
\hline Diuretics, $n(\%)$ & $72(83.7)$ & $125(83.3)$ \\
\hline Statins, $n(\%)$ & $80(93.0)$ & $139(92.7)$ \\
\hline Anti-platelet, $n(\%)$ & $86(100)$ & $150(100)$ \\
\hline $\begin{array}{l}\text { Anti-diabetes } \\
\text { medications, } n(\%)\end{array}$ & $30(34.9)$ & $54(36)$ \\
\hline Insulin, n (\%) & $9(10.5)$ & $13(8.7)$ \\
\hline LVEF (\%) & $31.7 \pm 3.0$ & $39.2 \pm 4.1^{*}$ \\
\hline NYHA-I/II, $n(\%)$ & $32(37.2)$ & $68(45.3)^{\star}$ \\
\hline NYHA-III/IV, $n(\%)$ & $54(62.8)$ & $82(54.7)^{\star}$ \\
\hline
\end{tabular}

Abbreviations the same as Table I; ${ }^{*} p<0.05$ vs. low LVEF group.
Table III. Association of LVEF and parameters of interest (OR and $95 \% \mathrm{Cl})$

\begin{tabular}{|c|c|c|}
\hline Variables & Univariate & Multivariate \\
\hline Age [years] & $0.95(0.92-0.99)$ & $0.98(0.94-1.06)$ \\
\hline Male gender & $1.01(0.94-1.10)$ & NS \\
\hline Current smoker & $0.92(0.87-1.01)$ & NS \\
\hline BMI $\left[\mathrm{kg} / \mathrm{m}^{2}\right]$ & $1.03(0.95-1.09)$ & NS \\
\hline Hypertension & $0.95(0.90-1.06)$ & NS \\
\hline Diabetes mellitus & $0.93(0.90-1.07)$ & NS \\
\hline $\mathrm{SBP}[\mathrm{mm} \mathrm{Hg}]$ & $0.99(0.95-1.12)$ & NS \\
\hline $\mathrm{HR}[\mathrm{bpm}]$ & $1.02(0.97-1.13)$ & NS \\
\hline $\mathrm{TC}[\mathrm{mmol} / \mathrm{l}]$ & $1.12(1.04-1.21)$ & $1.07(1.03-1.12)$ \\
\hline $\mathrm{TG}[\mathrm{mmol} / \mathrm{l}]$ & $1.04(0.97-1.11)$ & NS \\
\hline $\mathrm{ALB}[\mathrm{g} / \mathrm{l}]$ & $1.18(1.11-1.25)$ & $1.11(1.06-1.18)$ \\
\hline $\mathrm{ALT}[\mathrm{U} / \mathrm{I}]$ & $0.97(0.91-1.10)$ & NS \\
\hline $\mathrm{HbA}_{1 \mathrm{c}}(\%)$ & $0.99(0.94-1.08)$ & NS \\
\hline CRP $[\mathrm{mg} / \mathrm{l}]$ & $0.90(0.84-0.96)$ & $0.94(0.90-0.98)$ \\
\hline NT-proBPN [pg/ml] & $0.92(0.89-0.97)$ & $0.96(0.93-1.04)$ \\
\hline $\mathrm{ACEI} / \mathrm{ARB}$ & $1.09(1.03-1.17)$ & $1.05(1.01-1.10)$ \\
\hline$\beta$-Blocker & $1.03(0.99-1.10)$ & NS \\
\hline Spironolactone & $1.07(1.03-1.13)$ & $1.04(1.01-1.08)$ \\
\hline Diuretic & $0.97(0.92-1.03)$ & NS \\
\hline Statins & $1.02(0.95-1.08)$ & NS \\
\hline
\end{tabular}

Abbreviations the same as Table I, NS - non-significant.

Table IV. Linear regression analysis

\begin{tabular}{|lc|}
\hline Variable & TC (OR and 95\% Cl) \\
\hline Unadjusted & $1.21(1.13-1.30)$ \\
\hline Model 1 & $1.17(1.09-1.23)$ \\
\hline Model 2 & $1.12(1.05-1.18)$ \\
\hline Model 3 & $1.08(1.02-1.11)$ \\
\hline Model 4 & $1.04(0.99-1.06)$ \\
\hline
\end{tabular}

Model 1 adjusted for age, male gender, and smoking status; Model 2 adjusted for age, male gender, smoking status, hypertension, diabetes mellitus, ALT and NT-proBNP; Model 3 adjusted for age, male gender, smoking status, hypertension, diabetes mellitus, ALT, NT-proBNP, ACEI/ARB and spironolactone; Model 4 adjusted for age, male gender, smoking status, hypertension, diabetes mellitus, $A L T, N T$-proBNP, ACEI/ARB, spironolactone and CRP.

was still associated with an increment of $4 \%$ in LVEF, it did not achieve statistical significance.

\section{Discussion}

Our current study has the following principal findings. First of all, compared to those with moderately reduced LVEF, patients with severely re- 
duced LVEF appeared to have a poorer nutritional condition and greater systemic inflammation. Second, higher serum levels of TC and ALB were independently associated with higher LVEF while higher CRP level was significantly associated with lower LVEF. Finally, per 1 - SD increase in serum TC level was independently associated with a $4 \%$ increase in LVEF although it did not achieve statistical significance after adjustment for serum CRP level.

According to the 2013 AHA/ACC dyslipidemia guidelines [11], patients with documented CHD should be treated with intensive statins. Nevertheless, in patients with HF caused by CHD, neither the 2013 AHA/ACC heart failure guidelines [16] nor the 2016 ESC heart failure guidelines [17] provided a definite recommendation for cholesterol management because no randomized clinical trials have evaluated the optimal serum cholesterol level in these patients. Notably, statins has pleiotropic effects in terms of anti-inflammation, anti-oxidation and endothelium-protection [18], and therefore it was speculated that statins might have potential benefits for HF patients. Two randomized clinical trials $[19,20]$ have been performed to investigate whether statin therapy could improve cardiovascular outcomes in patients with $\mathrm{HF}$, regardless of the causes of left ventricular dysfunction. Disappointingly, these two trials did not show benefits for improvement of cardiovascular outcomes in the rosuvastatin group versus placebo group.

From a pathophysiological perspective, HF patients have a status of energy deprivation due to the increased heart rate and breathing rate both at rest and during physical activity. In addition, malnutrition caused by intestinal edema further reduces the energy source, which leads HF patients to gradually develop cardiac cachexia. Of note, both glucose and cholesterol are important substrates for energy generation and maintenance of organ function. Therefore, a higher serum cholesterol level may be beneficial for improvement of HF patients' outcome. Indeed, prior observational studies showed that compared to those with a low serum TC level, patients with a high serum TC level have a better prognosis. For example, Horwich et al. reported that in patients with acute decompensated HF [21], lower serum TC level independently predicted increased in-hospital mortality risk. In patients with advanced HF [13], Horwich et al. observed that after adjustment for traditional risk factors, decreased serum TC level was associated with nearly a 2 -fold increase in mortality risk. However, the causes of left ventricular dysfunction in these two studies were mixed. Recently, Cai et al. retrospectively enrolled patients with HF complicated by CHD [15], and they found that lower high-density lipoprotein cholesterol (HDL-C) level was associated with all-cause mor- tality in HF with reduced ejection fraction. Zhao et al. also observed that higher baseline TC and $\mathrm{HDL}-\mathrm{C}$ levels were associated with better outcome in CHD patients with HF [12]. Consistently with previous studies, our current study also showed that compared to those with severely reduced LVEF, patients with moderately reduced LVEF had significantly higher serum TC and ALB levels. Findings from multivariate regression analyses also supported the notion that increased serum TC and ALB levels were significantly associated with higher LVEF. The underlying mechanisms might involve increased supply of energy substrates, which in turn helped maintain cardiac function [15].

Interestingly and importantly, we also observed that increased serum CRP level was associated with lower LVEF; and in the linear regression analysis, after adjustment for serum CRP level, the odds ratio of per 1 - SD increase in serum TC level for LVEF change was reduced to statistical insignificance, indicating that the effects of increased serum TC level on protecting cardiac function might be associated with anti-inflammation. Sandek et al. [22] enrolled chronic HF patients and evaluated the morphology and function of the gut in these participants. They observed that compared to the control group, the intestinal permeability and bacterial biofilm were profoundly increased in patients with chronic HF, and they hypothesized that these pathologic alterations in turn might contribute to the origin of both chronic inflammation and malnutrition [22]. Notably, lipoprotein in the circulation system can combine endotoxins derived from bacteria of the intestinal tract [23-25]. Therefore, maintaining a higher cholesterol level might help to reduce the serum free endotoxin level in HF patients, which in turn may help to ameliorate systemic inflammation [26]. Indeed, in our current study we also observed that patients with higher LVEF had a higher serum ALB level and a lower serum CRP level when compared to patients with lower LVEF.

The clinical relevance of our current study is that in patients with HF caused by CHD, evaluating baseline serum TC level may be beneficial to assess the potential risk of left ventricular function worsening, which in turn would help physicians to better stratify the cardiovascular disease risk as well as to improve clinical management. Future prospective cohort studies and randomized controlled trials are warranted to evaluate whether changes of serum TC level over time will impact cardiovascular outcomes in HF caused by CHD.

In conclusion, in patients with HF complicated by CHD, higher serum TC level appeared to be associated with higher LVEF, and the underlying mechanisms might be associated with systemic inflammation improvement. The potential clinical implication of the current study is that it is war- 
ranted to investigate whether baseline serum TC level can be used to predict LVEF change and cardiovascular outcome in HF complicated by CHD.

There were some limitations of the current study. First of all, the cross-sectional design could not allow us to infer a causal relationship between serum TC level and LVEF. However, to our best knowledge, this is the first study to investigate the association of TC and LVEF in patients with HF complicated with CHD. Also, the findings from the current study provide novel insight into the association of serum TC level and LVEF in this unique population group. Second, although we had extensively adjusted for potential biases, undetected and unmeasured covariates might exist and impact the association. Third, the study was compromised by the relatively small sample size. Fourth, the study did not enroll HF patients with normal LVEF ( $>55 \%$ ), and future studies are needed to investigate whether serum TC level is also associated with LVEF in this population group. Last but least, not all patients enrolled in the study were treated with optimal medications, for example, only $36 \%$ of participants took spironolactone, which might also influence the association of serum TC level and LVEF, and these findings should not be extrapolated to other patients with optimal treatment.

\section{Acknowledgments}

We greatly appreciate Dr. Fang Huang for assisting us to perform statistical analysis and Dr. Congwu Zhang for revising our paper.

\section{Conflict of interest}

The authors declare no conflict of interest.

\section{References}

1. McMurray JJ, Stewart S. Epidemiology, aetiology, and prognosis of heart failure. Heart 2000; 83: 596-602.

2. Bui AL, Horwich TB, Fonarow GC. Epidemiology and risk profile of heart failure. Nat Rev Cardiol 2011; 8: 30-41.

3. Alagiakrishnan K, Banach M, Ahmed A, Aronow WS. Complex relationship of obesity and obesity paradox in heart failure - higher risk of developing heart failure and better outcomes in established heart failure. Ann Med 2016; 48: 603-13.

4. Seed M, Hoppichler F, Reaveley D, et al. Relation of serum lipoprotein(a) concentration and apolipoprotein(a) phenotype to coronary heart disease in patients with familial hypercholesterolemia. N Engl J Med 1990; 322: 1494-9.

5. Stamler J, Daviglus ML, Garside DB, Dyer AR, Greenland P, Neaton JD. Relationship of baseline serum cholesterol levels in 3 large cohorts of younger men to longterm coronary, cardiovascular, and all-cause mortality and to longevity. JAMA 2000; 284: 311-8.

6. Wilson PW, Myers RH, Larson MG, Ordovas JM, Wolf PA, Schaefer EJ. Apolipoprotein E alleles, dyslipidemia, and coronary heart disease. The Framingham Offspring Study. JAMA 1994; 272: 1666-71.

7. Lee TH, Cleeman JI, Grundy SM, et al. Clinical goals and performance measures for cholesterol management in secondary prevention of coronary heart disease. JAMA 2000; 283: 94-8.

8. Johannesson M, Jönsson B, Kjekshus J, Olsson AG, Pedersen TR, Wedel H. Cost effectiveness of simvastatin treatment to lower cholesterol levels in patients with coronary heart disease. Scandinavian Simvastatin Survival Study Group. N Engl J Med 1997; 336: 332-6.

9. LaRosa JC, Grundy SM, Waters DD, et al. Intensive lipid lowering with atorvastatin in patients with stable coronary disease. N Engl J Med 2005; 352: 1425-35.

10. Banach M, Jankowski P, Jóźwiak J, et al. PoLA/CFPiP/PCS Guidelines for the Management of Dyslipidaemias for Family Physicians 2016. Arch Med Sci 2017; 13: 1-45.

11. Stone NJ, Robinson JG, Lichtenstein AH, et al. 2013 ACC/ AHA guideline on the treatment of blood cholesterol to reduce atherosclerotic cardiovascular risk in adults: a report of the American College of Cardiology/American Heart Association Task Force on Practice Guidelines. Circulation 2014; 129 (25 Suppl 2): S1-45.

12. Zhao Q, Li J, Yang J, Li R. Association of total cholesterol and HDL-C levels and outcome in coronary heart disease patients with heart failure. Medicine (Baltimore) 2017; 96: e6094.

13. Horwich TB, Hamilton MA, Maclellan WR, Fonarow GC. Low serum total cholesterol is associated with marked increase in mortality in advanced heart failure. J Card Fail 2002; 8: 216-24.

14. Bielecka-Dabrowa A, Mikhailidis DP, Hannam S, Aronow WS, Rysz J, Banach M. Statins and dilated cardiomyopathy: do we have enough data. Expert Opin Investig Drugs 2011; 20: 315-23.

15. Cai A, Li X, Zhong Q, et al. Associations of high HDL cholesterol level with all-cause mortality in patients with heart failure complicating coronary heart disease. Medicine (Baltimore) 2016; 95: e3974.

16. Yancy CW, Jessup M, Bozkurt B, et al. 2013 ACCF/AHA guideline for the management of heart failure: a report of the American College of Cardiology Foundation/ American Heart Association Task Force on practice guidelines. Circulation 2013; 128: e240-327.

17. Ponikowski P, Voors AA, Anker SD, et al. 2016 ESC Guidelines for the diagnosis and treatment of acute and chronic heart failure: The Task Force for the diagnosis and treatment of acute and chronic heart failure of the European Society of Cardiology (ESC). Developed with the special contribution of the Heart Failure Association (HFA) of the ESC. Eur J Heart Fail 2016; 18: 891-975.

18. Cai A, Zhou Y, Li L. Rho-GTPase and atherosclerosis: pleiotropic effects of statins. J Am Heart Assoc 2015; 4: e002113.

19. Kjekshus J, Apetrei E, Barrios V, et al. Rosuvastatin in older patients with systolic heart failure. N Engl J Med 2007; 357: 2248-61.

20. Tavazzi L, Maggioni AP, Marchioli R, et al. Effect of rosuvastatin in patients with chronic heart failure (the GISSI-HF trial): a randomised, double-blind, placebo-controlled trial. Lancet 2008; 372: 1231-9.

21. Horwich TB, Hernandez AF, Dai D, Yancy CW, Fonarow GC. Cholesterol levels and in-hospital mortality in patients with acute decompensated heart failure. Am Heart J 2008; 156: 1170-6.

22. Sandek A, Bauditz J, Swidsinski A, et al. Altered intestinal function in patients with chronic heart failure. J Am Coll Cardiol 2007; 50: 1561-9. 
23. Sandek A, Bjarnason I, Volk HD, et al. Studies on bacterial endotoxin and intestinal absorption function in patients with chronic heart failure. Int I Cardiol 2012; 157: 80-5.

24. Tang WH, Wang Z, Fan Y, et al. Prognostic value of elevated levels of intestinal microbe-generated metabolite trimethylamine- $\mathrm{N}$-oxide in patients with heart failure: refining the gut hypothesis. I Am Coll Cardiol 2014; 64: 1908-14.

25. Miura S, Saku K. Effects of statin and lipoprotein metabolism in heart failure. J Cardiol 2010; 55: 287-90.

26. Pasini E, Aquilani R, Testa C, et al. Pathogenic gut flora in patients with chronic heart failure. JACC Heart Fail 2016; 4: 220-7. 